\title{
Comparison of Surface Conditioning Methods on Shear Bond Strength of Metal Brackets to Ceramic Surface - An in vitro study
}

Sameer R Dhakorkar' ${ }^{1}$ Vijay R Naik²

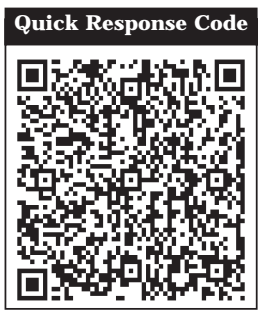

doi: $10.5866 / 2015.7 .10018$

P.G. Student ${ }^{1}$

Prof. \& H.O.D. ${ }^{2}$

Department of Orthodontics And Dentofacial Orthopedics, M.M.N.G.H.

Institute of Dental Science And Research Centre, Belgaum, Karnataka

\section{Article Info:}

Received: J anuary 9, 2015

Review Completed: February 8, 2015

Accepted: March 7, 2015

Available Online: April, 2015 (www.nacd.in)

(c) NAD, 2015 - All rights reserved

\section{Email for correspondence:}

dhakorkarsameer@gmail.com

\begin{abstract}
:
Aims and Objectives: The present study aimed to compare the shear bond strength of metal brackets on ceramic surfaces using different surface treatment methods. (i) 37\% Phosphoric acid (ii) $9 \% \mathrm{HF}$ (iii) Sand blasting $(50-120 \mu \mathrm{m})$ and (iv) Extra fine bur $(20-30 \mu \mathrm{m})$

Materials and method: Forty ceramic facets were taken, resembling maxillary central incisor labial surfaces with thickness of $2 \mathrm{~mm}$. They were divided into four groups. In Group 1 surfaces were treated with Phosphoric Acid 37\% and Silane. In Group 2 surfaces were treated with Hydrofluoric Acid $9 \%$ and Silane. In Group 3 surfaces were treated with sand blasting (50-120 $\mu \mathrm{m})$ and Silane. In Group 4 surfaces were treated using extra fine bur $(20-30 \mu \mathrm{m})$ and silane. Brackets were bonded to each conditioned ceramic surface with light curing composite resin. Then Specimens weretested on Universal testing machine for shear force required to debond the brackets. The Shear bond strength data were subjected to ANOVA Test.

Results: Surfaces conditioned with 9\% HFA showed the higher bond strength followed by sandblasting, extra fine bur and $37 \%$ phosphoric acid.

Conclusion: Shear bond strength of metal brackets bonded to ceramic surfaces using the four different surface conditioning methods were adequate. $37 \%$ Phosphoric acid is the choice of surface conditioning to ceramic surfaces, since it has adequate bond strength. It is least harmful to oral mucosa compared to 9\% Hydrofluoric acid and less cumbersome to use compared to Sandblasting and less destructive compared to extra fine bur.
\end{abstract}

Key words: Orthodontic bracket, Ceramic facets, Conditioning, Shear bond strength.

\section{INTRODUCTION}

As the demand for adult orthodontic treatment increases and the popularity of esthetic dentistry expands, orthodontists are more likely faced with the problem of placing orthodontic appliances on teeth restored with resin and porcelain fixed prostheses or veneer laminates. When esthetics is a concern, orthodontists will have to depend on the direct bonding technique. ${ }^{1}$
Buonocore introduced the acid-etch technique in 1955 by bonding acrylic resin to the enamel surface that had been pretreated with $85 \%$ phosphoric acid for 60 seconds. Since this initial report, various investigators have evaluated the technique to determine the factors that may effect the strength of the mechanical bond including: the type of enamel conditioner, acid concentration, and length of etching time. ${ }^{2}$

\section{Indian Journal of Dental Advancements Journal homepage: www. nacd. in}


Numerous conditioning methods have been suggested for pre-treating ceramic surfaces. ${ }^{3,4}$ Organosilane coupling agents are suggested to enhance bonding of brackets to ceramic. ${ }^{5}$ Hydrofluoric (HF) acid and acidulated phosphate fluoride were reported to facilitate micromechanical retention, but HF acid has been found to be a harmful and irritating compound for soft tissues. Furthermore, mechanical roughening with fine and coarse diamond burs and sandblasting are reported to provoke crack initiation and propagation within the ceramic. Because the restorations generally remain in the mouth after debonding the brackets, damage to the ceramic due to extreme roughening of the surfaces during pretreatment or debonding must be avoided. ${ }^{6}$ The present study aimed to compare the shear bond strength of metal brackets on ceramic surfaces using different surface treatment methods. (i) 37\% Phosphoric acid (ii) 9\% HF (iii) Sand blasting (50-120 $\mu \mathrm{m})$ and (iv) Extra fine bur (20-30 $\mu \mathrm{m})$.

\section{Materials and Methods}

Forty ceramic facets were taken, resembling maxillary central incisor labial surfaces with thickness of $2 \mathrm{~mm}$. These facets were placed on the metal casting. This entire casting along with ceramic facet was mounted in the dental plaster. They were divided into four groups (Figure 1).

Group 1: Surfaces treated with Phosphoric Acid $37 \%$ (60seconds) and Silane.

Group 2: Surfaces treated with Hydrofluoric Acid $9 \%$ (90seconds) and Silane.

Group 3: Surfaces treated with sand blasting (50$120 \mu \mathrm{m})$ and Silane.

Group 4: Surfaces treated using extra fine bur (2030 $\mu \mathrm{m})$ and Silane.

Facets in each group were mounted vertically on dental plaster blocks. Facets were aligned with the facial surface of the tooth perpendicular with the bottom of the mold; i.e., each tooth was oriented so its labial surface would be parallel to the force during the shear strength test.

Transbond XT bonding system (3M Unitek) containing a liquid sealant and an adhesive paste, is used for bonding. Manufacturer's instructions were followed throughout the procedure. All fourty Ceramic facets were conditioned according to groups. Application of silane coupling agent (UItradent) done on conditioned facets with mini brush tip. Stainless steel central incisor metal brackets, (3M Unitek, Gemini M.B.T, Monorovia ,USA) used for bonding.
After bonding all specimens were stored at $37^{\circ} \mathrm{C}$ for $24 \mathrm{hrs}$ in water to prevent dehydration of the specimens. ${ }^{7-10}$

A Customized jig was suspended from the crosshead of a UNIVERSALTESTING MACHINE (TUE-C-400, Fine Spavy Associates \& Engineers Pvt. Ltd.,Miraj). A Gingivo-occlusal load was applied to de-bond the bracket, producing shear force at the bracket-tooth interface for all the four groups (Figure 2). A computer, el ectronically connected with the test machine, recorded the results of each test. Shear bond strengths were measured at a crosshead speed of $0.5 \mathrm{~mm} / \mathrm{min}$.

Statistical Analysis: Mean shear bond strength of different groups was determined using student $t$ test. The level of significance ( $p$ value) was kept at 0.05. The Shear bond strength data were subjected to ANOVA Test.

\section{Results}

Surfaces conditioned with 9\% HFA showed the higher bond strength $(14.12 \pm 2.11 \mathrm{MPa})$ followed by Sandblasting (13.14 $\pm 1.30 \mathrm{MPa})$, Extra fine bur $(11.71 \pm 2.13 \mathrm{MPa})$ and $37 \%$ Phosphoric acid (11.05 $\pm 2.13 \mathrm{MPa})(\mathrm{Graph}$ I; Table 1). Statistically significant variations existed in the shear bond strength in group I with group II and group III; group II and group IV; and group III and group IV (Table 2 and 3) (Pd"0.05).

\section{Discussion}

It is important to prepare ceramic surfaces prior to bonding. Numerous types of acid etching solution with variable concentrations have been devel oped. These include hydrofluoric acid (HFA) gel (Zachrisson et al. 1996; Kocadereliet al. 2001), acidulated phosphate fluoride (APF; Major et al. 1995), and phosphoric acid gel and solutions (Yen et al. 1993). The most commonly used ceramic acid etchant is a 9.6 per cent HFA gel (Stangelet al. 1987). ${ }^{11}$

There are few scientifically-based recommendations in the literature for a minimum orthodontic bracket shear bond strength .Whitlock et al. (1994), based upon the work of Reynolds, also suggested that 6-8MPa was adequate for orthodontic attachments and this was used in the present study. ${ }^{12}$ The present study was conducted to find the most reliable method for bonding metal brackets onto ceramic crowns.

In the present study the silane application was combined with mechanical or chemical roughening to increase SBS. Silane application following surface 
Table 1: Mean, SD, standard error and coefficient of variation of shear bond strength in four groups

\begin{tabular}{lcccc} 
Groups & Mean & SD & SE & CV \\
HF & 14.12 & 2.11 & 0.67 & 14.97 \\
\hline Extra fine bur & 11.71 & 2.13 & 0.67 & 18.17 \\
\hline 37\%phosporic acid & 11.05 & 1.94 & 0.61 & 17.54 \\
\hline Sandblasted & 13.14 & 1.30 & 0.41 & 9.91 \\
\hline
\end{tabular}

Table 2: Comparison of four groups (HF, Extra fine bur, 37\%phosporic acid, Sandblasted) with respect to shear bond strength by one way ANOVA

\begin{tabular}{|c|c|c|c|c|c|}
\hline $\begin{array}{l}\text { Source of } \\
\text { variation }\end{array}$ & $\begin{array}{c}\text { Sum } \\
\text { of } \\
\text { squares }\end{array}$ & $\begin{array}{c}\text { Degrees } \\
\text { of } \\
\text { freedom }\end{array}$ & $\begin{array}{l}\text { Mean } \\
\text { sum of } \\
\text { squares }\end{array}$ & $\begin{array}{c}\text { F- } \\
\text { value }\end{array}$ & $\begin{array}{l}\text { P- } \\
\text { value }\end{array}$ \\
\hline $\begin{array}{l}\text { Between } \\
\text { groups }\end{array}$ & 57.63 & 3 & 19.21 & \multirow[t]{3}{*}{5.3207} & \multirow[t]{3}{*}{$0.0039 *$} \\
\hline $\begin{array}{l}\text { Within } \\
\text { groups }\end{array}$ & 129.99 & 36 & 3.61 & & \\
\hline Total & 187.62 & 39 & & & \\
\hline
\end{tabular}

Table 3: Pair wise comparison of four groups (HF, Extra fine bur, $37 \%$ phosporic acid, Sandblasted) with respect to shear bond strength by Newman-Keuls multiple posthoc procedures

\begin{tabular}{|c|c|c|c|c|}
\hline Groups & HF & $\begin{array}{l}\text { Extra } \\
\text { fine } \\
\text { bur }\end{array}$ & $\begin{array}{l}37 \% \\
\text { phosporic } \\
\text { acid }\end{array}$ & $\begin{array}{l}\text { Sand } \\
\text { blasted }\end{array}$ \\
\hline Mean & 14.1210 & 11.7110 & 11.0500 & 13.1410 \\
\hline SD & 2.1134 & 2.1274 & 1.9379 & 1.3020 \\
\hline $\mathrm{HF}$ & - & & & \\
\hline $\begin{array}{l}\text { Extra } \\
\text { fine bur }\end{array}$ & $P=0.0200 *$ & - & & \\
\hline $\begin{array}{l}37 \% \\
\text { phosporic } \\
\text { acid }\end{array}$ & $P=0.0050 *$ & $P=0.4419$ & - & \\
\hline $\begin{array}{l}\text { Sand } \\
\text { blasted }\end{array}$ & $P=0.2565$ & $P=0.1012$ & $P=0.0483^{*}$ & - \\
\hline
\end{tabular}
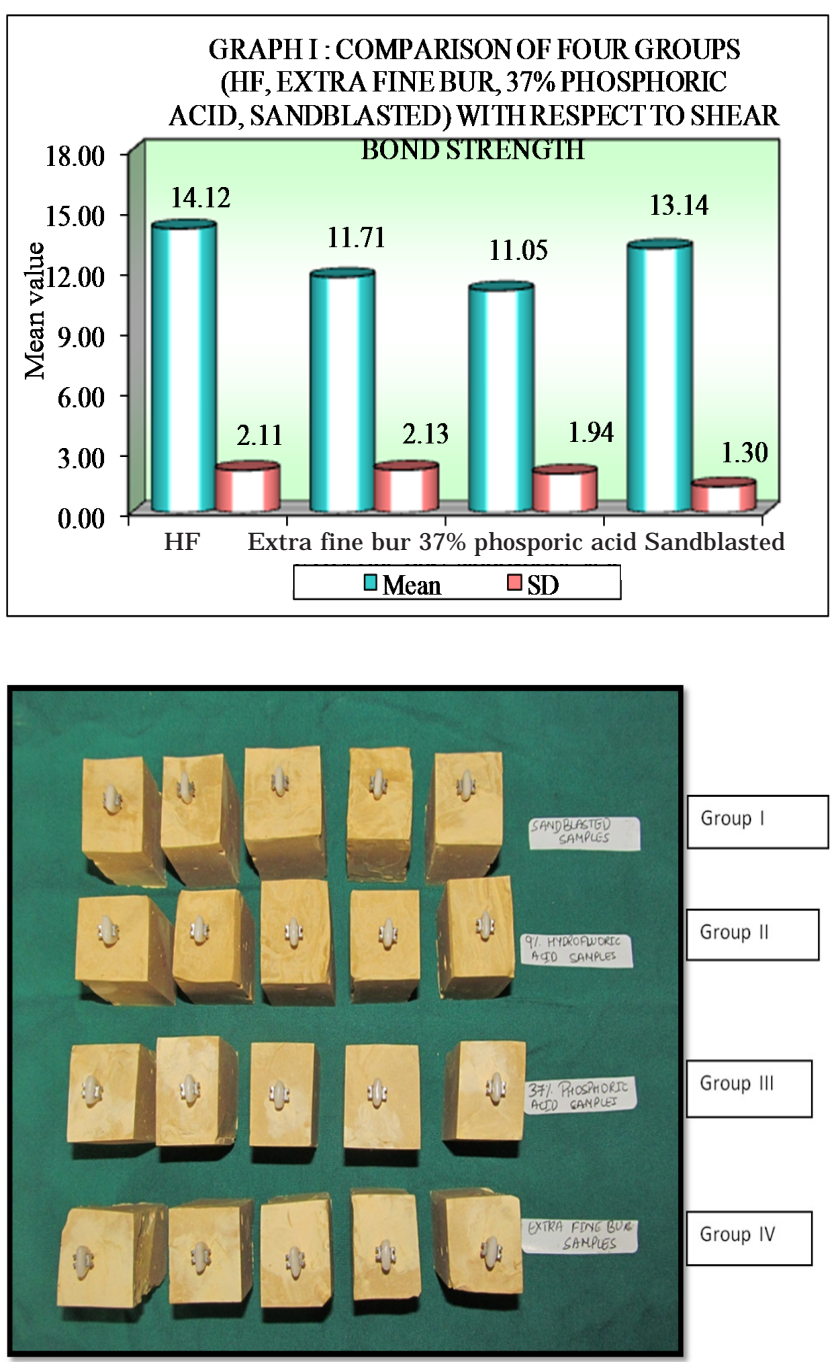

Figure 1: Samples Consisted of Four Test Groups (10 in Each Group). Group I: Surfaces treated with Phosphoric Acid 37\% (60seconds) and Silane. Group II: Surfaces treated with Hydrofluoric Acid $9 \%$ (90seconds) and Silane. Group III : Surfaces treated with sand blasting $(50-120 \mu \mathrm{m})$ and Silane. Group IV: Surfaces treated using extra fine bur $(20-30 \mu \mathrm{m})$ and Silane.
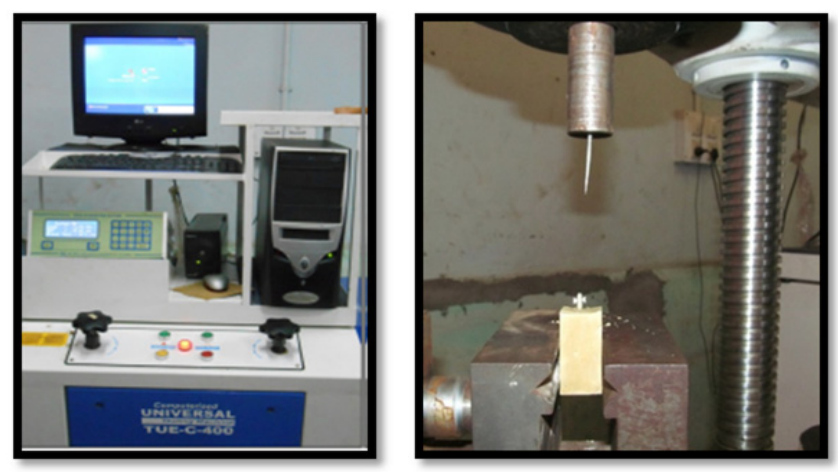

Figure 2: Universal testing machine and customized jig with specimen. (a) Universal testing Machine

(b) Customized J ig with specimen. 
roughening provides a statistically significant increase in SBS (Wood et al. 1986; Kao et al. 1988; Smith et al. 1988; Kao and J ohnston, 1991; Whitlock et al. 1994; Cochran et al. 1997; Chung et al. 1999; Huang and Kao, 2001; Kocadereli et al. 2001; Schmage et al. 2003). Silane presents a chemical link between the dental ceramic and the composite resin, and the organic portion of the molecule enhances the wettability of the ceramic surface, thereby displaying a closer micromechanical bond (Luet al.1992 ). ${ }^{3,5}$

In present study, extra fine bur group showed higher shear bond strength than phosphoric acid group, but less than HFA and Sand blasted group. Roughening the porcelain surface with a extra fine diamond, produced a random peeling appearance thus enlarging the porcelain surface area with only shallow mechanical retention. ${ }^{13}$ However, the differences were not observed among the groups, i.e. roughening with a diamond bur, chemical etching with HFA, and APA (Air particle abrasion) with $\mathrm{Al}_{2} \mathrm{O}_{3}$ particles ( Sant'Annaet al. 2002). In another study, roughening with diamond burs without silane application showed lower bond strength than chemical etching with HFA with silane and APA with $\mathrm{Al}{ }_{2} \mathrm{O}_{3}$ particles with silane (Schmage et al. 2003). ${ }^{3}$

In present study, Sand blasted group showed comparable shear bond strength with that of $\mathrm{HF}$ group, slightly less which is not clinically significant. Sandblasting particles produced a uniform peeling appearance of the porcelain with deeper penetration and more undercuts compared to roughening; this increased potential mechanical retention. ${ }^{13}$

Glaze removal has been advocated in order to create mechanical retention for the adhesive agent (Hulterstromand Bergman, 1993). Unfortunately, glaze removal by a diamond bur or green stone may damage porcelain by scoring the surface and an additional disadvantage of glaze removal is a reduction of 50 per cent in transverse strength (Phillips, 1991). Sandblasting with microscopic particles of aluminium oxide to remove glaze may be better than using burs or stones since only a small amount of surface is removed and the procedure is more uniform (Zachrissonet al. 1996). ${ }^{4}$

Direct transfer of this valueto clinical situations is not universally accepted because the bracketceramic bond is influenced by many environmental factors. Even though the clinical relevance of in vitro studies is limited, they are essential in testing new methods before they can be used in vivo.

\section{Conclusion}

The following conclusions were drawn from the present study: Shear bond strength of metal brackets bonded to ceramic facets using the four different surface conditioning methods were adequate. On comparison of four different surface conditioning methods, $9 \%$ Hydrofluoric acid showed higher shear bond strength followed by sandblasting $(50-120 \mu \mathrm{m})$, extra fine bur $(20-30 \mu \mathrm{m})$ and $37 \%$ phosphoric acid respectively. 37\% Phosphoric acid is the choice of surface conditioning to ceramic surfaces, since it has adequate bond strength. It is least harmful to oral mucosa compared to $9 \%$ Hydrofluoric acid and less cumbersome to use compared to sandblasting and less destructive compared to extra fine bur.

\section{References}

1. Ahmad Akhoundi MS et al. Assessment of bond strength between metal brackets and non-glazed ceramic in different surface treatment methods. J Dent 2010; 7(2):64-70.

2. Olsen ME, Bishara SE, Damon P, J akobsen J R.. Evaluation of scotchbond multipurpose and maleic acid as alternative methods of bonding orthodontic brackets. Am J Orthod Dentofacial Orthop 1997; 111:498-501.

3. Turk T, Sarac D, Sarac YS, Turk SE. Effects of surface conditionings on bond strength of metal brackets to all ceramic surfaces. Eur J Orthod 2006 Oct; 28(5):450-456.

4. Bourke BM, Rock WP. Factors affecting the shear bond strength of orthodontic brackets to porcelain. $\mathrm{Br}$ J Orthod 1999; 26(4):285-290.

5. Major PW, Koehler J R, Manning KE. $24 \mathrm{hr}$ shear bond strength of metal orthodontic brackets bonded to porcelain using various adhesion promoters. AmJ Orthod Dentofacial Orthop 1995; 108(3):322-329.

6. Schmage $P$ et al. Influence of various surface-conditioning methods on the bond strength of metal brackets to ceramic surfaces. Am J Orthod Dentofacial Orthop 2003; 123:540-6.

7. Aida M, Hayakawa T, Mizukawa K. Adhesion of composite to porcelain with various surface conditions.J Prosthet Dent 1995; 73:464-470.

8. Nebbe B, Stein E. Orthodontic brackets bonded to glazed and deglazed porcelain surfaces. AM J Orthod Dentofacial Orthop 1996; 109:431-436.

9. Cochran D, Okeefe KL, Turner DT, Powers J M. Bond strength of orthodontic composite cement to treated porcelain.Am J Orthod Dentofacial Orthop 1997; 111:297300.

10. Kocadereli I, Canay S, Akça K. Tensile bond strength of ceramic orthodontic brackets bonded to porcelain surfaces. Am J Orthod Dentofacial Orthop 2001; 119:617-620.

11. Abu Alhaija EJ , Abu AIReesh IA, AIWahadni AS. Factors affecting the shear bond strength of metal and ceramic brackets bonded to different ceramic surfaces. Eur J Orthod 2010; 32:274-280.

12. Reynolds IR. A review of direct orthodontic bonding. $\mathrm{Br}$ J Orthod.1975; 2(3):171-178.

13. Gillis I, Redlich M.The effect of different porcelain conditioning techniques on shear bond strength of stainless steel brackets. Am J Orthod Dentofacial Orthop1998; 114:387-392. 